\title{
Un visitante en la ruta del migrante. Experiencia en Los Chiles, Costa Rica
}

Daywing Duarte, sj.

Escolar jesuita. Correo electrónico: winday79@yahoo.com

La zona de río San Juan siempre ha sido un importante lugar de paso de emigrantes nicaragüenses hacia Costa Rica. Desde los años 90 lo es mucho más. La inmensa mayoría de quienes transitan por esa ruta con la ayuda de los "coyotes", pasan el río y son conducidos hacia los naranjales cercanos a la línea fronteriza, donde a su suerte buscan un espacio abierto y sin vigilancia para cruzar la frontera.

Durante el mes de enero de 2008, tuve la oportunidad de conocer el trabajo del Servicio Jesuita para Migrantes (SJM) en Costa Rica. Pude ver que, por un lado, los problemas migratorios entre Nicaragua y Costa Rica parecen encontrar soluciones y que, por el otro, las llagas continúan abiertas. Por ello, con este escrito intento compartir parte de mi experiencia en el SJM, en particular la experiencia en la comunidad de Los Chiles.

Como parte del trabajo visité la comunidad de Los Chiles, ubicada a $6 \mathrm{Km}$. de la frontera entre Costa Rica y Nicaragua. El pueblo es relativamente pequeño y cuenta con la presencia de casi todas las instituciones del Estado. Por su ubicación geográfica se ha constituido en un lugar de paso para migrantes nicaragüenses. Para llegar al pueblo, desde Nicaragua, se pueden seguir dos rutas, una por el río Frío de manera legal, procediendo de San Carlos; la otra, cruzando el río San Juan y caminando hasta la frontera para pasar de forma ilegal por las plantaciones de naranjas.

La travesía de los nicaragüenses incluye viaje en bus desde cualquier parte del país, especialmente del norte y del centro, hasta San Carlos. Luego se paga transporte por la rivera del San Juan hasta un punto donde se aborda una panga que los cruza al otro lado del río. Ahí se negocia con un "coyote" que los transporta por una carretera de tierra que va desde ese punto del río hasta entroncar con la carretera de la frontera del lado tico. Es interesante notar que del lado tico el asfalto inicia justo en el alambrado que divide la frontera. Es un paso literal del polvo al asfalto. Los "coyotes" nicas detienen su marcha antes de llegar a la frontera tica y hacen que la gente siga el camino a pie por los naranjales, que para mayor paradoja, son de capitales mixtos nicaragüenses y costarricenses o de compañías radicadas en Costa Rica que cultivan en tierra nica. Y por supuesto, el producto lo sacan por el lado tico. La gente camina en dirección del alambrado, lejos del puesto de frontera. Cruza el alambrado y sigue por el monte hasta llegar a la carretera, un kilómetro más allá del puesto fronterizo por el lado tico. 
En todo el viaje la gente corre el riesgo de quedarse sin dinero en el intento por llegar a la frontera. Los "coyotes" se encargan de eso. Luego viene la fatiga de la caminada, que castiga más a los niños. Para ahorrar un poco, usualmente las y los migrantes no comen nada desde que salen de San Carlos. Muchos prefieren esperar la noche para pasar, según ellos, sin ser vistos. Una vez del otro lado, corren el riesgo de ser atrapados y luego deportados. Al final terminan cansados, con hambre y sin dinero. Muchos sin esperanzas y esperando la deportación. No olvidan que una vez deportados, aunque en Nicaragua, aún están lejos de sus hogares y sin dinero.

Hasta hace unos años atrás, los migrantes capturados eran detenidos y encarcelados en las instalaciones de migración en un lugar conocido como "el hueco", ubicado en el sótano del ya viejo y deteriorado edificio en el que están las oficinas de Migración. Según se comenta, las condiciones eran precarias, sin camas ni servicio sanitario. En el lugar se encerraba a hombres, mujeres y niños que hacinados, esperaban su deportación. No tenían comida ni espacio para dormir. Hay que imaginar cómo se vería ese pequeño espacio en temporada alta para las migraciones.

En vista de ello, un Fraile Franciscano, asumiendo las responsabilidades que el gobierno y las instituciones costarricenses no asumían y en atención a la dignidad de las personas detenidas, inició su labor cristiana intentando acondicionar "el hueco" con algunas camas y comida. Además, realizó protestas a favor de mejorar las condiciones. Hoy, "el hueco" sólo guarda basura, camas viejas, mal olor, barrotes corroídos, paredes manchadas con escritos que descargaron la furia de los migrantes que alguna vez estuvieron encerrados en ese lugar y sombras de dolorosos recuerdos, sueños truncados e intentos fallidos.

Con su labor, los Frailes Franciscanos y los Hermanos Maristas lograron fundar en el pueblo el albergue para migrantes Nuestra Señora de Guadalupe. También lograron que Migración permitiera que las mujeres y los menores de edad capturados pasaran la noche en el albergue. De esta manera, sólo los varones mayores de edad pasan la noche en las instalaciones del comando de la Policía, acondicionado para ese fin. Además de acoger a mujeres y menores de edad, el albergue también facilita la cena a los varones mayores de edad detenidos en el comando.

El albergue es una casa grande de dos plantas. Tiene una sala pequeña con televisión, donde algunas personas descansan antes de dormir. Cuenta con cinco cuartos con varias literas, según el tamaño de cada cuarto. De esta manera las personas pueden contar con una cama cómoda para pasar la noche; en caso de ser muchos, también se acomodan colchones en el suelo. Cuanta con dos baños y duchas muy limpios y en buenas condiciones, uno en cada planta. El comedor y la cocina son pequeños pero muy limpios y presentan buenas condiciones. Las personas comen por grupos según vayan llegando por la noche. El apoyo consiste en brindarles la cena, albergue por una noche y el desayuno.

El número de personas que acoge el albergue varía según las circunstancias y los meses del año. A finales de diciembre e inicios de enero el número incrementa a 30 personas por noche y en algunas ocasiones han llegado hasta 80 personas en una noche. Según se aprecia, la administración de los Hermanos Maristas ha sido muy positiva. Impresiona la limpieza y el 
orden que le dan a la casa un toque familiar y acogedor. En la noche todas las instalaciones están limpias e impecables, la mesa puesta, las camas hechas, la comida caliente y una acogida cálida.

En el albergue se reciben personas remitidas por la parroquia a cargo de los Frailes Franciscanos Menores y los Hermanos Maristas, administradores del albergue. Otras son remitidas por el Consulado de Nicaragua en Los Chiles; por la Policía, que remite a mujeres y menores capturados; y por el hospital, que envía a personas pobres de las comunidades cercanas que no tienen dónde pasar la noche. Para el ingreso de las personas, es necesario presentar una boleta elaborada por cualquiera de estas instituciones. Con la boleta se lleva el control de las personas que ocupan el albergue. El albergue cuenta con una señora encargada de preparar la cena y el desayuno y un señor encargado de recibir a las personas por la noche y hacer de guarda de seguridad.

Paralelo al trabajo del albergue, me impactó el trabajo que realizan los "coyotes" o "talibanes", como le llaman en la zona a quienes se dedican a cruzar a los nicaragüenses de manera ilegal. Es toda una industria. Para hacer su trabajo más eficiente, los del lado tico se comunican con los del lado nica por celular y así se ponen de acuerdo sobre los lugares en donde unos dejan a la gente para que los otros la reciban y transporten hacia el pueblo en Costa Rica o hacia el rio en Nicaragua. Los del lado tico están pendientes de los policías que patrullan la carretera y así avisan sobre los espacios disponibles para que la gente pase.

Es muy común escuchar de los migrantes capturados que los "coyotes" les cobran y que al final los dejan en lugares en donde la policía los puede atrapar con facilidad. Usualmente se pagan quince dólares por persona para hacer el viaje desde el San Juan hasta el alambrado de la frontera por los naranjales. Los "coyotes" nicas ubican algún espacio por donde se pueda pasar por el monte sin ser vistos y asegurando que del otro lado los "coyotes" ticos estarán esperando. Si la gente logra hacer la conexión con los del lado tico, éstos les cobran cinco dólares más por llevarlos hasta el pueblo.

Por otro lado, años atrás los Hermanos Maristas emprendieron una campaña de concientización para los oficiales y policías del comando de la fuerza pública y los de Migración. Según comenta uno de los hermanos, esto ha dado muchos frutos. Ha mejorado el trato a las y los migrantes y las condiciones físicas para retenerlos hasta el momento de su deportación. Otro de los grandes logros fue conseguir que los policías coloquen en sus uniformes una placa con su nombre y número de placa, de manera que el migrante que reciba maltrato pueda dar cuenta del nombre o número del policía. En caso de denuncia en el albergue, los Hermanos llaman al comandante de la estación y ponen la denuncia. En su momento fueron suspendidos varios oficiales. Todo esto ha contribuido a mejorar el trato de la Policía con el migrante, hecho que pude constatar con las mujeres que la Policía llevaba al albergue. Según me comentaban, los policías son muy amables y educados. "Cuando nos agarran en el camino son muy amables, nos alumbran con el foco por el monte y nos tratan bien”, me comentó una señora que fue atrapada con su hermana y sus tres niños.

Al ser un lugar de paso, la gran mayoría de las y los migrantes que logran pasar abandonan Los Chiles en pocas horas. No obstante, existe en el lugar y las comunidades cercanas un gran número de nicaragüenses que trabajan en las plantaciones de naranjas, piñas 
y en otras ocupaciones. Para ellos, la pastoral social llevada por los Hermanos ha hecho algunos talleres sobre manipulación de alimentos y otros de diversa temática. Actualmente se está trabajando en dos prioridades: facilitar talleres sobre autoestima para los y las nicaragüenses, y realizar campañas de concientización entre la población de la zona. Cabe destacar que la labor a nivel institucional de crear conciencia y mejorar condiciones se ha ido logrando también en parte por la participación directa de los Hermanos en la red de instituciones que la pastoral social convoca. En ésta participan los directores de la mayoría de las instituciones del gobierno presentes en el pueblo, el Consulado de Nicaragua y la Iglesia Católica.

Otra obra social que aportan a los migrantes es la guardería infantil que recibe a los niños -en su mayoría nicaragüenses- antes o después del período de clases, para facilitar que los padres puedan trabajar y los niños no estén solos en sus casas. Se logra que las personas pobres y en buenas condiciones físicas puedan buscar alternativas de trabajo mientras sus hijos quedan seguros y atendidos durante el día.

Este año la Policía costarricense junto con Migración montó un operativo especial en las zonas fronterizas. Aumentaron las patrullas de frontera, los efectivos, los retenes en las carreteras y hasta se lanzaron a patrullar en el monte por las noches. Los noticieros en varias ocasiones presentaban el tema de la gran cantidad de migrantes que eran deportados de ambos puestos fronterizos y en su mayoría del puesto en Los Chiles.

Me he limitado a contar lo que observé y escuché en mi estadía en Los Chiles, y mis viajes en bicicleta hasta la frontera para ver el movimiento de los “coyotes", los migrantes y la Policía. No puedo negar el gran impacto que esta realidad ha dejado en mí. Es difícil describir el sentimiento y lo que la experiencia ha significado. Ver las lágrimas, el dolor y el espanto de las mujeres, los niños y las niñas que conocí en el albergue, el lamento del dolor en los pies y del hambre que los más pequeños les expresaban a sus madres me partía el corazón. Al final, todos se acostaban pensando en que el descanso era sólo por una noche. Al día siguiente, muy temprano, la tristeza y la desesperanza volvían a los rostros de aquella gente que subía a la patrulla para su deportación. 
orden que le dan a la casa un toque familiar y acogedor. En la noche todas las instalaciones están limpias e impecables, la mesa puesta, las camas hechas, la comida caliente y una acogida cálida.

En el albergue se reciben personas remitidas por la parroquia a cargo de los Frailes Franciscanos Menores y los Hermanos Maristas, administradores del albergue. Otras son remitidas por el Consulado de Nicaragua en Los Chiles; por la Policía, que remite a mujeres y menores capturados; y por el hospital, que envía a personas pobres de las comunidades cercanas que no tienen dónde pasar la noche. Para el ingreso de las personas, es necesario presentar una boleta elaborada por cualquiera de estas instituciones. Con la boleta se lleva el control de las personas que ocupan el albergue. El albergue cuenta con una señora encargada de preparar la cena y el desayuno y un señor encargado de recibir a las personas por la noche y hacer de guarda de seguridad.

Paralelo al trabajo del albergue, me impactó el trabajo que realizan los "coyotes" o "talibanes", como le llaman en la zona a quienes se dedican a cruzar a los nicaragüenses de manera ilegal. Es toda una industria. Para hacer su trabajo más eficiente, los del lado tico se comunican con los del lado nica por celular y así se ponen de acuerdo sobre los lugares en donde unos dejan a la gente para que los otros la reciban y transporten hacia el pueblo en Costa Rica o hacia el rio en Nicaragua. Los del lado tico están pendientes de los policías que patrullan la carretera y así avisan sobre los espacios disponibles para que la gente pase.

Es muy común escuchar de los migrantes capturados que los "coyotes" les cobran y que al final los dejan en lugares en donde la policía los puede atrapar con facilidad. Usualmente se pagan quince dólares por persona para hacer el viaje desde el San Juan hasta el alambrado de la frontera por los naranjales. Los "coyotes" nicas ubican algún espacio por donde se pueda pasar por el monte sin ser vistos y asegurando que del otro lado los "coyotes" ticos estarán esperando. Si la gente logra hacer la conexión con los del lado tico, éstos les cobran cinco dólares más por llevarlos hasta el pueblo.

Por otro lado, años atrás los Hermanos Maristas emprendieron una campaña de concientización para los oficiales y policías del comando de la fuerza pública y los de Migración. Según comenta uno de los hermanos, esto ha dado muchos frutos. Ha mejorado el trato a las y los migrantes y las condiciones físicas para retenerlos hasta el momento de su deportación. Otro de los grandes logros fue conseguir que los policías coloquen en sus uniformes una placa con su nombre y número de placa, de manera que el migrante que reciba maltrato pueda dar cuenta del nombre o número del policía. En caso de denuncia en el albergue, los Hermanos llaman al comandante de la estación y ponen la denuncia. En su momento fueron suspendidos varios oficiales. Todo esto ha contribuido a mejorar el trato de la Policía con el migrante, hecho que pude constatar con las mujeres que la Policía llevaba al albergue. Según me comentaban, los policías son muy amables y educados. "Cuando nos agarran en el camino son muy amables, nos alumbran con el foco por el monte y nos tratan bien”, me comentó una señora que fue atrapada con su hermana y sus tres niños.

Al ser un lugar de paso, la gran mayoría de las y los migrantes que logran pasar abandonan Los Chiles en pocas horas. No obstante, existe en el lugar y las comunidades cercanas un gran número de nicaragüenses que trabajan en las plantaciones de naranjas, piñas 
y en otras ocupaciones. Para ellos, la pastoral social llevada por los Hermanos ha hecho algunos talleres sobre manipulación de alimentos y otros de diversa temática. Actualmente se está trabajando en dos prioridades: facilitar talleres sobre autoestima para los y las nicaragüenses, y realizar campañas de concientización entre la población de la zona. Cabe destacar que la labor a nivel institucional de crear conciencia y mejorar condiciones se ha ido logrando también en parte por la participación directa de los Hermanos en la red de instituciones que la pastoral social convoca. En ésta participan los directores de la mayoría de las instituciones del gobierno presentes en el pueblo, el Consulado de Nicaragua y la Iglesia Católica.

Otra obra social que aportan a los migrantes es la guardería infantil que recibe a los niños -en su mayoría nicaragüenses- antes o después del período de clases, para facilitar que los padres puedan trabajar y los niños no estén solos en sus casas. Se logra que las personas pobres y en buenas condiciones físicas puedan buscar alternativas de trabajo mientras sus hijos quedan seguros y atendidos durante el día.

Este año la Policía costarricense junto con Migración montó un operativo especial en las zonas fronterizas. Aumentaron las patrullas de frontera, los efectivos, los retenes en las carreteras y hasta se lanzaron a patrullar en el monte por las noches. Los noticieros en varias ocasiones presentaban el tema de la gran cantidad de migrantes que eran deportados de ambos puestos fronterizos y en su mayoría del puesto en Los Chiles.

Me he limitado a contar lo que observé y escuché en mi estadía en Los Chiles, y mis viajes en bicicleta hasta la frontera para ver el movimiento de los “coyotes", los migrantes y la Policía. No puedo negar el gran impacto que esta realidad ha dejado en mí. Es difícil describir el sentimiento y lo que la experiencia ha significado. Ver las lágrimas, el dolor y el espanto de las mujeres, los niños y las niñas que conocí en el albergue, el lamento del dolor en los pies y del hambre que los más pequeños les expresaban a sus madres me partía el corazón. Al final, todos se acostaban pensando en que el descanso era sólo por una noche. Al día siguiente, muy temprano, la tristeza y la desesperanza volvían a los rostros de aquella gente que subía a la patrulla para su deportación. 